\section{The buzzer as a primary aversive stimulus: III. Unconditioned and conditioned suppression of barpress avoidance}

\author{
DAVE RIESS \\ Galesburg State Research Hospital, Galesburg, Ill. 61401
}

Eight rats with extensive experience on a Sidman schedule were given 1-min buzzer presentations (Experiment 1) to test the unconditioned properties of buzzers on barpress avoidance. Four additional rats (Experiment 2) were given light-buzzer pairings superimposed on avoidance. Contrary to previous results with rats for aversive and preaversive stimuli in the shuttlebox, both procedures produced response suppression in the Skinner box. This reduction in avoidance ranged widely from nearly $100 \%$ for five $\mathrm{Ss}$ in the buzzer procedure ("unconditioned" suppression) to $5 \%-20 \%$ in the light-buzzer procedure (conditioned suppression).
Previous studies of the effects of preaversive stimuli on avoidance behavior in rats have produced a striking discrepancy which is clearly related to the apparatus employed. The usual result of such a procedure is an increase in avoidance rates during the CS. This phenomenon is termed "conditioned acceleration," to contrast it with conditioned suppression, the normal result when an aversive Pavlovian CS+ is superimposed on an appetitive operant baseline. The avoidance increases reported for such stimuli with rats have usually been obtained in the shuttlebox apparatus Kamano, 1968, 1970a, b; Martin \& Riess, 1969; Riess, 1969, 1970b, c, 1971; Riess \& Bath, 1970; Riess \& Martin, 1969). However, when the preaversive stimuli are superimposed on the avoidance behavior of rats in a Skinner box, suppression seems to be the normal result (Blackman, 1970; Brady, Libber, \& Dardano, 1967; Hurwitz \& Roberts, 1969; Roberts \& Hurwitz, 1970). Previous results to date with buzzer and prebuzzer stimuli (Riess, 1970b, c) are uniformly in the direction of acceleration when the apparatus is a shuttlebox. The present effort examines the effects of noncontingent buzzer and prebuzzer stimuli on free operant avoidance in the Skinner box.

EXPERIMENTT 1:

\section{UNCONDITIONED SUPPRESSION \\ OF BARPRESS AVOIDANCE WITH NONCONTINGENT BUZZER PRESENTATIONS Subjects}

The Ss were eight naive male albino Wistar rats. They were taken from the Galesburg Psychology Laboratory colony when they were between 72 and 92 days of age and caged individually at the start of the

\section{Apparatus}

The experimental chamber was a (Herendeen \& Anderson, 1968; experiment.
Model E 3125B-100 $29 \times 25 \times 20 \mathrm{~cm}$ two-lever barpress, of which only the right bar was operative for this experiment. The bar was $1 \mathrm{~cm}$ thick, $6 \mathrm{~cm}$ wide, projected $1 \mathrm{~cm}$ into the box, and located $9 \mathrm{~cm}$ above the grid. A 32-g dead weight was required to depress it over a $2-\mathrm{mm}$ excursion to produce a response. The chamber was housed in a Model E3125AA-3 sound-attenuated chest and programmed by a solid-state Series 1200 modular system with a 1231 control panel and a 1231-2 plug board. Additional equipment included a Model 901B white-noise generator, a Model E-1064GS combination shock generator and scrambler, a 1208 power supply, a Model 1238 three-channel cumulative digital printer, and a Model 1209 28-V power supply. Specific modules used for programming were two 100 -sec timers, two 10-sec timers, a $S$ station interface, an AND gate, an OR gate, cumulative counters recording shocks, responses, and session length were also in use. The printout counter recorded interresponse times on one channel and shocks preceding each response on another. All equipment was from Grason-Stadler Co., except for a Dayton Co. Model 1 C939 blower, which circulated fresh air into the sound chest.

The UCS was a 76-phon buzzer described previously (Riess, 1970b) and was located exterior to the chamber, but inside the sound chest. The CS was a $60-\mathrm{W}$ red light.

\section{Procedure}

All eight Ss rapidly acquired barpress avoidance with a shaping technique described previously (Riess, $1970 \mathrm{a})$. After three to five 4-h sessions at the terminal parameters $(\mathrm{R}-\mathrm{S}=30 \mathrm{sec}, \mathrm{S} \cdot \mathrm{S}=5 \mathrm{sec}$, shock $=.1 \mathrm{sec}, 2 \mathrm{~mA}$ ), Ss were begun on 1-min buzzer presentations. A 2 -min baseline preceding the 1-min UCS yielded a rate change formula of $2 B /(A+2 B)$. Sessions were from 3 to $5 \mathrm{~h}$, depending on length of warm-up and number of presentations per session. At least $15 \mathrm{~min}$ were always allowed to elapse before the first presentation, between any two presentations, and between the last presentation and session termination. The "aftereffect" (i.e., the ratio of pre-CS to post-CS responding) was recorded for Sessions 1-6 for S 14, Sessions 12-15 for $S 28$, and Sessions 7-13 for S 35. The number of presentations per session varied from 2 to 6 . This was continued for 20 buzzer presentations in five $S s$ and for 38 presentations in three Ss. and an output control. Three

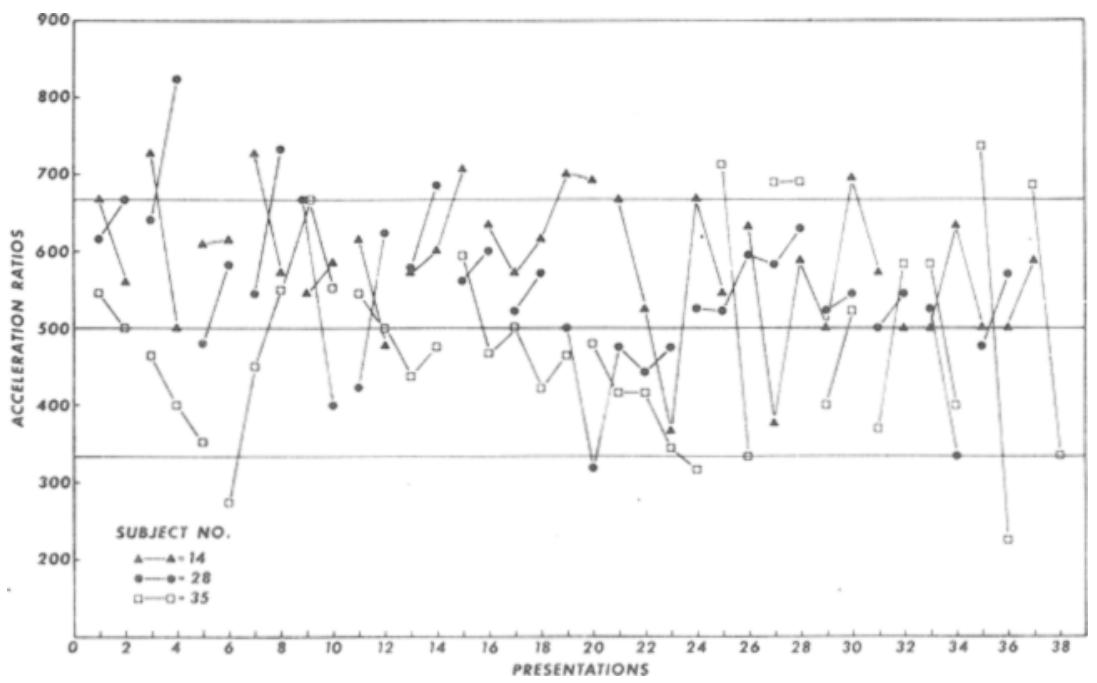

Fig. 1. Changes in responding during 1 -min buzzer presentations for three of eight $S_{s}$ who maintained relatively intact response levels. The suppression ratios were derived from the formula $2 B /(A+2 B)$. The number of presentations per session are indicated by the connecting lines. 


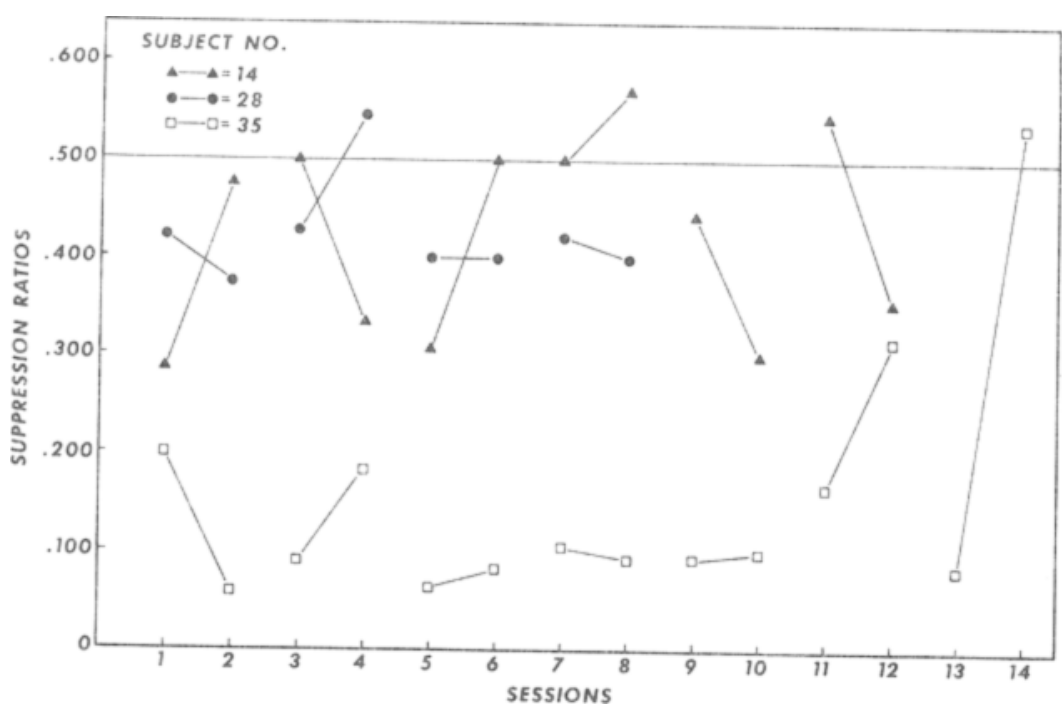

Fig. 2. "Inhibitory aftereffects" for the same three Ss for 1-min postbuzzer intervals.

\section{Results}

Six of the eight Ss initially suppressed and continued to do so for the first three sessions. Five of these Ss were dropped after 20 presentations, when it became obvious that all responding except that following shocks was almost completely eliminated. In three of these five Ss, even the S-S responding ceased and they routinely "sat out" the buzzer intervals, receiving shocks every 5 sec. Two Ss accelerated reliably and continued to do so. Data for the only three Ss who retained responding are presented in Fig. 1 for all 38 buzzer presentations.

The horizontal lines are included to

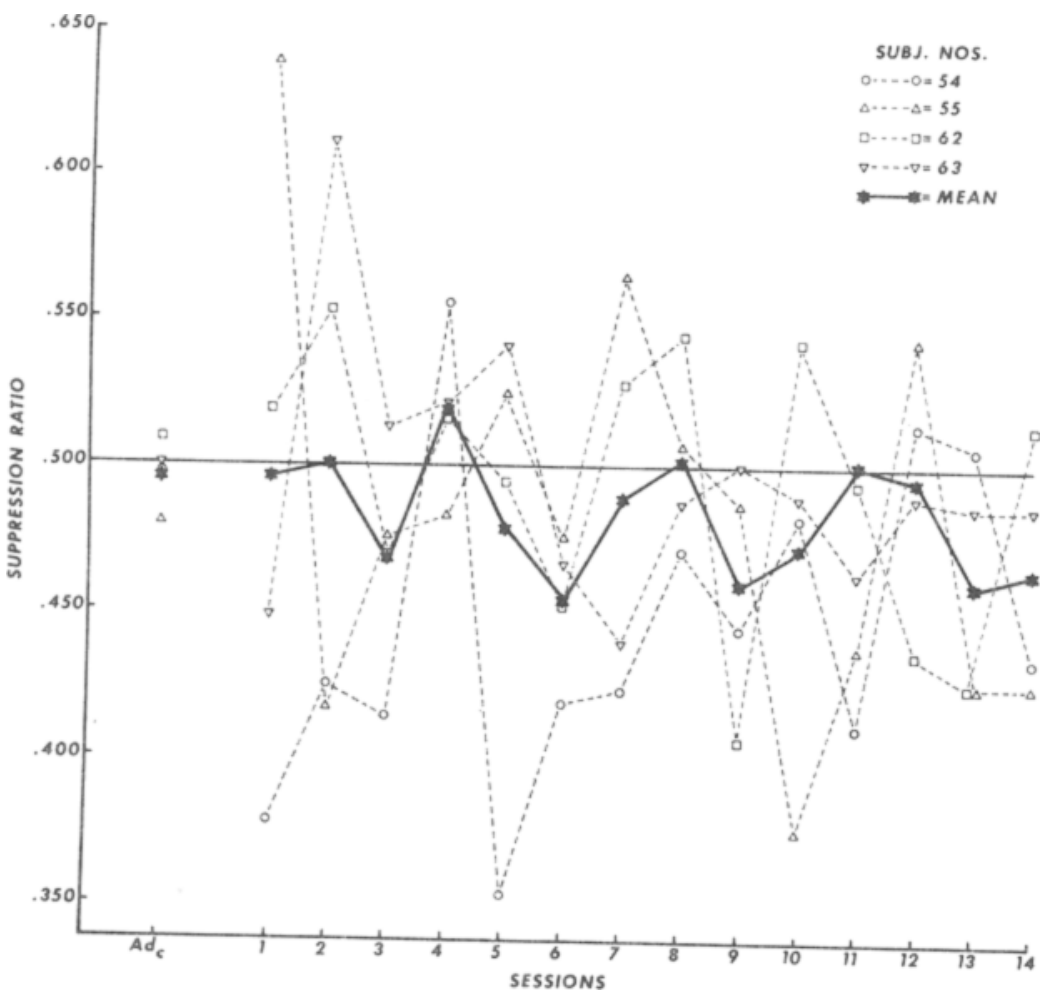

Fig. 3. Suppression ratios for light responding when $\mathrm{CS}$ is unreinforced $\left(\mathrm{Ad}_{\mathrm{c}}\right)$ and reinforced with a 5 -sec buzzer UCS. enhance visibility, the .667 line indicating a doubling of rate and the .333 line indicating a halving of rate. $\mathrm{S} 14$ accelerated (.500 or higher) on $92 \%$ of the presentations, $S 28$ on $75 \%$, and $S 35$ on $45 \%$. The percentage was zero for all five $S s$ who received 20 presentations.

The data on aftereffects (Fig. 2) was all consistently in the direction of suppression and ranged from moderate in Ss 14 and 28 to severe in S 35, whose responding was completely eliminated for some of the minutes following the buzzer.

The postbuzzer responding of the five other Ss during the first 20 presentations was also severely suppressed. One of these Ss received 17 consecutive shocks from one buzzer onset until the first postbuzzer response occurred.

EXPERIMENT 2:

\section{CONDITIONED SUPPRESSION OF BARPRESS AVOIDANCE WITH NONCONTINGENT PREBUZZER STIMULI \\ Subjects and Apparatus}

The Ss were four experienced avoiders with 4-5 months of barpress experience on various Sidman schedules. The apparatus was identical to that in Experiment 1.

\section{Procedure}

The Ss were run through the following three-step sequence of treatments:

(1) Sidman avoidance consisted of 18 sessions of $2-h$ free operant avoidance sessions to allow stabilization prior to introduction of the buzzer presentations. Each response postponed the next shock $20 \mathrm{sec}$ (R-S interval), and shocks followed each other every 5 sec (S-S interval) in the absence of a response. The shocks were $.15 \mathrm{sec}, 1.0 \mathrm{~mA}$. The above parameters were made identical to those used in the shuttlebox (Riess, $1970 \mathrm{c}$ ) so that any discrepancies in the results of the two studies could be unequivocally attributed to the apparatus difference.

(2) Adaptation was identical to Step 1, except that five 30 -sec red light presentations occurred each session. These were given so that at least $5 \mathrm{~min}$ elapsed between any two light presentations, between the start of the session and the first presentation, and between the last presentation and the termination of the session. A rate change ratio was computed from the formula $\mathrm{CSR}=2 \mathrm{~B} /(\mathrm{A}+2 \mathrm{~B})$, where $\mathrm{CSR}=$ conditioned suppression ratio, $A=$ responding during the $1 \mathrm{~min}$ preceding the light, and $B=$ responding during the light. This was continued until each $S$ met a criterion of two consecutive sessions with the mean CSR for all 10 
presentations between .475 and .525 .

(3) Paulovian conditioning was identical to Step 2, except that 5 -sec buzzer presentations occurred at the end of the light. The light period was extended 5 sec, yielding a coterminous delay paradigm. Responding during the buzzer was ignored in computing the CSR. Step 3 was continued for 14 sessions.

\section{Results}

The avoidance rates prior to classical conditioning averaged about $6.5+$ responses/min, and shocks occurred about once every $4 \mathrm{~min}$. Adaptation was relatively routine as all four Ss reached criterion in the third session.

The results of the last 2 days of adaptation $\left(\mathrm{Ad}_{\mathrm{c}}\right)$ and conditioning (Fig. 3) show that the light produced a gradual change from "neutrality" during adaptation toward suppression, which became progressively more evident across sessions. Although the suppression evident here is not pronounced, this is due largely to the fact that the Sidman schedule remained in effect and the responding could not attenuate severely without shocks occurring (floor effect). The IRT patterns during the CS indicated that there was a gross suppression of responses in the 5- to 15 -sec IRT range but an increase in the number of responses in the 0 - to $4-\mathrm{sec}$ range and also in the $20+$ range. The shock rates during the CS increased disproportionately to the total reduction in responding. This tendency was found to some extent in all Ss but was marked in $S 63$, whose CS responding in the 5- to 19-sec IRT range had been almost completely eliminated by the last four sessions. The light stimulus, unlike the buzzer alone in Experiment 1, was never able to suppress S-S responding, so that while the IRT pattern was altered drastically, the ratios do not reflect fully the reduced tendency to respond, owing to the frequent shock-elicited bursting which inflated the ratios. DISCUSSION

The present finding of response suppression produced by buzzer and prebuzzer stimuli in the barpress apparatus is in conflict with results obtained under virtually identical parameters in the shuttlebox (Riess, $1970 \mathrm{~b}, \mathrm{c})$ but is in agreement with the results for preshock stimuli in the Skinner box (Blackman, 1970; Brady et al, 1967; Hurwitz et al, 1969; Roberts et al, 1970). The apparatus inconsistency in the results with prebuzzer stimuli exactly parallels the corresponding inconsistency with preshock stimuli. Thus, the only generalization defensible about the effects of preaversive stimuli on avoidance behavior which can encompass all of the findings is that such a procedure will produce changes in accord with the apparatus employed (i.e., acceleration in the shuttlebox and suppression in the Skinner box) and not in accord with the nature of the aversive event (i.e., shock vs buzzer), although even this generalization must, at present, be confined to rats. The hypothesis that the buzzer constitutes a primary aversive stimulus and any phenomena obtainable with shocks are essentially replicable with buzzers receives further support from the present experiments, although it does indicate that, in the special case of Pavlovian CS+ effects on avoidance, the definition of "aversiveness" cannot a priori be equated with acceleration but must make appropriate allowances for apparatus differences. With this qualification, the results do support the hypothesis that a buzzer constitutes a primary aversive stimulus, as previously demonstrated by Myers (1965), in the case of escape behavior.

\section{BLA CKM AN DFERENCES}

. Conditioned suppression of avoidance behavior in rats. Quartexly Journal of Experimental Psychology, 1970, 22, 547-553.

BRADY, J. V., LIBBER, S.. \& DARDANO, J. Some effects of a preaversive stimulus on avoidance behavior. Space Research Laboratory Technical Report No.67-14, 1967.

HERENDEEN, D., \& ANDERSON, D. C. conditioned stimulus: Excitation and inhibition. Psychonomic Science, 1968, $13,15-16$.

HURWITZ, H. M. B., \& ROBERTS, A. E. Suppressing an avoidance response by a pre-aversive stimulus. Psychonomic Science, 1969, 17, 305-306.

KAM ANO, D. K. Effects of an extinguished fear stimulus on avoidance behavior. Psych onomic Science, 1968, 13, 271-272.

KAMANO, D. $K$. Types of Pavlovian conditioning procedures used in establishing CSt and their effect upon avoidance behavior. Psychonomic Science, 1970a, 18, 63-64.

KAMANO, D. K. Effects of a Pavlovian conditioned fear stimulus on avoidance performance attenuated by experimental extinction. Psychonomic Science, 1970b. 21, 187-188.

MARTIN, L. K., \& RIESS, D. Effects of US intensity during preliminary discrete delay conditioning on conditioned acceleration during avoidance extinction. Journal of Comparative \& Physiological Psychology, 1969, 69, 196-200。

MYERS, A. K. Instrumental escape conditioning to a low-intensity noise by rats. Journal of Comparative \& Physiological Psychology, 1965, 60, 8287.

RIESS, D. Pavlovian phenomena in conditioned acceleration: Stimulus summation. Conditional Reflex, 1969,4, 25 7-264.

RIESS, D. A shaping technique for producing rapid and reliable Sidman barpress avoidance. Journal of the Experimental Analysis of Behavior, 1970a, 13, 279-280.

RIESS, $D$. The buzzer as a primary aversive stimulus: I. Unconditioned acceleration and summation of conditioned and unconditioned acceleration. Psychonomic Science, 1970b, 21, 167-169.

RIESS. D. The buzzer as a primary aversive stimulus: II. Unavoidable buzzer presentations and conditioned acceleration. Psychonomic Science, 1970c, 21, 302-304.

RIESS, D. Vicarious conditioned acceleration: Successful observational learning of an aversive Pavlovian stimulus contingency. Journal of the Experimental Analy sis of Behavior, 1971, in press.

RIESS, D., \& BATH, J. Operant and Pavlovian stimulus control of avoidance latencies in conditioned acceleration. Psychonomie Science, 1970, 19, 165-167.

RIESS, D.. \& MARTIN, L. K. Effects of UCS intensity during continuing coterminous delay conditioning on conditioned acceleration during maintained avoidance. Psychonomic Science, 1969, 16, 251-252.

ROBERTS, A. E。 \& HURWITZ, H. M. B. The effects of a pre-shock signal on a free-operant avoidance response. Journal of the Experimental Analysis of Behavior, $1970,14,331-340$. 